University of Rhode Island

DigitalCommons@URI

Civil \& Environmental Engineering Faculty

Publications

Civil \& Environmental Engineering

1981

\title{
Quantitative method for enumeration of enterotoxigenic Escherichia coli.
}

\author{
Rebecca L. Calderon \\ Morris A. Levin \\ University of Rhode Island
}

Follow this and additional works at: https://digitalcommons.uri.edu/cve_facpubs

Terms of Use

All rights reserved under copyright.

\section{Citation/Publisher Attribution}

Calderon R. L., \& Levin, M. A. (1981). Quantitative Method for Enumeration of enterotoxigenic Escherichia coli. J. Clin. Microbiol., 13(1), 130-134. Retrieved from http://jcm.asm.org/content/13/1/130.

Available at: http://jcm.asm.org/content/13/1/130

This Article is brought to you for free and open access by the Civil \& Environmental Engineering at DigitalCommons@URI. It has been accepted for inclusion in Civil \& Environmental Engineering Faculty Publications by an authorized administrator of DigitalCommons@URI. For more information, please contact digitalcommonsgroup@uri.edu. 


\title{
Quantitative Method for Enumeration of Enterotoxigenic Escherichia coli
}

\author{
REBECCA L. CALDERON'† AND MORRIS A. LEVIN $\ddagger^{2} *$ \\ U.S. Environmental Protection Agency Marine Field Station, Health Effects Research Laboratory- \\ Cincinnati, West Kingston, Rhode Island $02892,{ }^{2}$ and University of Rhode Island, Kingston, Rhode Island \\ $02881^{1}$
}

A rapid method was developed to quantify toxigenic Escherichia coli, using a membrane filter procedure. After filtration of samples, the membrane filter was first incubated on a medium selective for $E$. coli $\left(24 \mathrm{~h}, 44^{\circ} \mathrm{C}\right)$ and then transferred to tryptic soy agar $\left(3 \% ; 6 \mathrm{~h}, 37^{\circ} \mathrm{C}\right)$. To assay for labile toxin-producing colonies, the filter was then transferred to a monolayer of Y-1 cells, the $E$. coli colonies were marked on the bottom of the petri dish, and the filter was removed after 15 $\mathrm{min}$. The monolayer was observed for a positive rounding effect after a 15- to 24$h$ incubation. The method has an upper limit of detecting 30 toxigenic colonies per plate and can detect as few as one toxigenic colony per plate. A preliminary screening for these enterotoxigenic strains in polluted waters and known positive fecal samples was performed, and positive results were obtained with fecal samples only.

Diarrheal disease is a leading cause of death in underdeveloped countries as well as a significant cause of morbidity in adults $(8,12)$. In $25 \%$ of the cases, a known bacterial pathogen is isolated (i.e., Salmonella spp., Shigella spp., Vibrio cholerae, or Vibrio parahaemolyticus). It has been estimated that another 25 to $50 \%$ of the cases may be due to viral agents, leaving 25 to $50 \%$ with no known etiological agent. Escherichia coli, a normal inhabitant of the human intestinal tract, has demonstrated the ability to produce enterotoxins capable of causing diarrhea in humans and animals. There are two wellrecognized enterotoxins produced by this species, heat stable and heat labile (LT), which are clearly distinguishable from each other by their physical characteristics. Epidemiological evidence concerning the role of enterotoxigenic $E$. coli (ETEC) as a cause of gastrointestinal illness in the United States is conflicting and unclear. Part of the problem has been due to a lack of a rapid method for quantifying ETEC when processing large numbers of clinical and environmental samples. The development of such a method should permit clarification of epidemiological data as well as promote genetic and mechanisms of pathogenesis studies.

This study was designed to develop a rapid, relatively inexpensive, and quantitative procedure for determining the number of LT-produc-

† Present address: Yale University School of Public Health, New Haven, CT 06510.

‡ Present address: Office of Exploratory Research, U.S. Environmental Protection Agency, Washington, DC 20460. ing ETEC present in fecal or environmental samples or both. Since membrane filtration techniques provide a quantitative method of isolating certain species from mixed populations by use of selective media $(6,10)$, a membrane filter technique (mTEC) specific for $E$. coli (4) was used for isolating $E$. coli. This procedure allows identification of $E$. coli colonies before assaying for toxin production, thus eliminating the problem of false-positives and cytopathic effects of toxins produced by organisms other than $E$. coli. This technique was combined with the sensitive Y-1 cell assay to permit rapid identification of LT-producing $E$. coli colonies.

\section{MATERIALS AND METHODS}

Bacterial strains. $E$. coli toxigenic strains K344, $\mathrm{K} 325, \mathrm{~K} 100$, M117, and M324 were provided by R. B. Sack (Johns Hopkins Medical Research Center, Baltimore, Md.). Strain 10405 was an $E$. coli strain maintained by this laboratory. All strains except 10405 were shown to be toxigenic by the Y-1 cell assay (2).

Toxin preparations. Crude enterotoxin preparations were prepared from 18- to 24-h cultures grown at $37^{\circ} \mathrm{C}$ on a shaker in $25-\mathrm{ml}$ flasks containing $5 \mathrm{ml}$ of $3.0 \%$ tryptic soy broth (TSB; Difco Laboratories, Detroit, Mich.). The cultures were then centrifuged (20 min, $1,200 \times g$ ), and the supernatant was decanted into sterile tubes containing $0.1 \mathrm{ml}$ of gentamicin (3 $\mathrm{mg} / \mathrm{ml}$ ).

Toxin levels in the agar under the membrane filters were assayed by removing agar plugs (using a sterile scalpel), and toxin was extracted from the agar in 0.5 $\mathrm{ml}$ of phosphate-buffered saline (PBS) (4), pH 7.2, containing $0.3 \mathrm{mg}$ of gentamicin per $\mathrm{ml}$, by suspending the agar in PBS for $24 \mathrm{~h}$ at $6^{\circ} \mathrm{C}$. 
The agar extract $(0.2 \mathrm{ml})$ and supernatant $(0.2 \mathrm{ml})$ were assayed for the presence of toxin within $24 \mathrm{~h}$ of preparation, using the $\mathrm{Y}-1$ procedure.

Cell culture. Y-1 adrenal cells were provided by the Center for Disease Control, Atlanta, Ga. They were cultivated as monolayer cultures at $37^{\circ} \mathrm{C}$ in a humidified atmosphere ( $95 \%$ air, $5 \%$ carbon dioxide). Cells were grown in Ham nutrient mixture F-10 supplemented with $15 \%$ horse serum and $2.5 \%$ fetal calf serum (GIBCO Laboratories, Grand Island, N.Y.). Logarithmic growth was maintained in stock cultures by periodic subculture. Cell suspensions were produced either by mechanical disruption with a rubber policeman followed by pipetting or by proteolytic disaggregation of the culture with a 10-min exposure to $0.1 \%$ trypsin (Microbiological Associates, Walkersville, Md.). To test crude toxin preparations, equal numbers of Y-1 cells $\left(10^{4}\right)$ were added to each well of an eightwell plate (Lux; Microbiological Associates) and allowed to grow for 2 to 3 days before use in assays. For membrane filter assay, higher densities of cells (more than $10^{5}$ cells per $\mathrm{ml}$ ) were distributed in $1.0-\mathrm{ml}$ quantities into petri dishes (60 by $15 \mathrm{~mm}$, gridded; Costar, Cambridge, Mass.) and allowed to grow for 2 days or to confluency. The tissue culture medium was changed before using the monolayer and replaced with F-10 (as described above) which contained $25 \mu \mathrm{g}$ of gentamicin per ml.

Membrane filtration. Samples were diluted in PBS as required to give 20 to 80 colonies per plate and filtered through Gelman filters (GN6). Filters were placed on mTEC agar, incubated for $2 \mathrm{~h}$ at $37^{\circ} \mathrm{C}$, and then placed at $44^{\circ} \mathrm{C}$ for 18 to $24 \mathrm{~h}$. To facilitate toxin production, the membrane filters then were aseptically transferred from the mTEC medium to $3.0 \%$ tryptic soy agar (TSA; Difco Laboratories) and incubated at $37^{\circ} \mathrm{C}$ for $6,8,10$, or $12 \mathrm{~h}$ before assaying for toxin. $\mathrm{Y}$ 1 monolayers were prepared for use by removing the medium and washing the cells two times with PBS. Only plates with confluent monolayers are selected for use. The filters were placed directly on the cell monolayer for 15,30 , or $45 \mathrm{~min}$. The bottom of each plate was marked, detailing the location of the $E$. coli colonies. The filters were removed aseptically, and the Y1 cells were washed two times with PBS; the $3 \mathrm{ml}$ of F-10 with $25 \mu \mathrm{g}$ of gentamicin per $\mathrm{ml}$ was added, and the monolayers were incubated for 15 to $24 \mathrm{~h}$ before being examined for positive results (Fig. 1).

mTEC medium. mTEC medium contains the following: proteose peptone no. $3,5.0 \mathrm{~g}$; yeast extract, 3.0 g; lactose, $10.0 \mathrm{~g} ; \mathrm{NaCl}, 7.5 \mathrm{~g} ; \mathrm{K}_{2} \mathrm{HPO}_{4}, 3.3 \mathrm{~g} ; \mathrm{KH}_{2} \mathrm{PO}_{4}$, $1 \mathrm{~g}$; sodium lauryl sulfate, $0.2 \mathrm{~g}$; sodium deoxycholate, $0.1 \mathrm{~g}$; bromocresol purple, $80 \mathrm{mg}$; bromophenol red, 80 $\mathrm{mg}$; agar, $15 \mathrm{~g}$; and distilled water to 1 liter. The ingredients are dissolved by stirring, sterilized by autoclaving at $121^{\circ} \mathrm{C}$ for $15 \mathrm{~min}$, and poured into plates (10 by $47 \mathrm{~mm}, 4 \mathrm{ml}$ per plate). An appropriate volume of each sample is filtered, and the filters are placed on the medium. The plates are sealed in Whirlpak bags and incubated at $35^{\circ} \mathrm{C}$ for $2 \mathrm{~h}$, after which they are immersed in water for $20 \pm 2 \mathrm{~h}$ at $44.5^{\circ} \mathrm{C}$. Lactosepositive colonies are scored, and the filters then are placed on pads saturated with urease reagent $(0.1 \%$

\section{DAY 1 a) Filter sample}

b) Incubate on mTEC

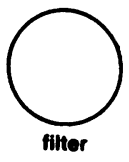

DAY 2 a) Count yellow colonies

b) Do ureaso tost and mark 1 all colonies that are not still yellow (only E. coli are bit)

c) Place on TSB medium for 6 hrs

d) Place filter on prepared $Y-1$ cell plate 2 for $15 \mathrm{~min}$

e) Mark on bottom of cell plate location of colonies

f) Remove fitter

g) Place media on $Y-1$ cell plate and incubate for $15 \mathrm{hr}$

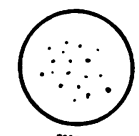

finor

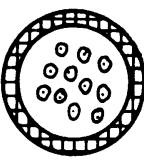

Y-1 plate with filter

DAY 3 a) Read plate microscopically

b) Examine colony areas for toxin reaction

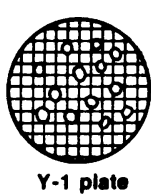

1 Mark by punching hole in filter.

2Plate selected for use with confluent monolayer

Fig. 1. mTEC procedure.

TABLE 1. Recovery of toxigenic strains of E. coli on mTEC medium

\begin{tabular}{|c|c|c|c|c|c|c|}
\hline \multirow{2}{*}{ Trial } & \multicolumn{6}{|c|}{ Recovery (\%) of strain } \\
\hline & $\mathrm{K} 325^{a}$ & K344“ & M324 & M117 & $\mathrm{K} 100^{\prime \prime}$ & $10405^{h}$ \\
\hline 1 & $66^{c}$ & 64 & 82 & 100 & 87 & 75 \\
\hline 2 & 81 & 70 & 93 & 100 & 100 & 100 \\
\hline Avg & 73 & 67 & 88 & 100 & 93 & 88 \\
\hline
\end{tabular}

" Toxigenic strain.

${ }^{b}$ Control strain (nontoxigenic isolate).

' Percent recovery relative to nutrient agar spread plates. Three replicate plates were used for each dilution.

urease in deionized water) and observed for $15 \mathrm{~min}$. Yellow colonies (urease negative) are $E$. coli.

\section{RESULTS}

Recovery of toxigenic strains. The use of membrane filters and the effectiveness of the mTEC medium as a recovery technique for toxigenic $E$. coli were examined. The percentage of ETEC strains recovered on MTEC medium was determined relative to that recovered on nutrient agar spread plates (Difco Laboratories) (Table 1). Recovery of the toxigenic strains (84 \pm $14 \%$ ) was similar to the recovery of nontoxigenic strains $(88 \pm 17 \%)$.

Toxin production and assay. Toxin production by ETEC has been demonstrated in several liquid media $(2,12)$, and results with strain K325 in this laboratory with mTEC medium without agar demonstrated that toxin was 
present in the supernatant after $18 \mathrm{~h}$ of incubation. However, the toxin was not detected in mTEC agar (Table 2). Despite the presence of toxin in the supernatant from the initial culture, no toxin was present in the MTEC agar beneath filters on which ETEC colonies had developed for the preceding 24 to $48 \mathrm{~h}$. In an effort to determine whether the medium, the temperature, or some other factor was inhibiting the production (or detectability) of toxin, the filter was transferred after the 18-h incubation period on mTEC medium to various media. By transferring the filters to TSA, toxin could be detected after $6 \mathrm{~h}$ (Table 3). An incubation period of less than $6 \mathrm{~h}$ on TSA usually resulted in a toxic effect on the Y-1 cells, although results were variable. This may have been due to a toxic

TABLE 2. Detection of LT in mTEC medium

\begin{tabular}{|c|c|c|c|c|}
\hline \multirow{3}{*}{ Organism } & \multicolumn{4}{|c|}{ Detection } \\
\hline & \multirow{2}{*}{$\begin{array}{l}\text { In superna- } \\
\operatorname{tant}^{a}\end{array}$} & \multicolumn{3}{|c|}{$\begin{array}{l}\text { After following } \\
\text { time (h) of incuba } \\
\text { tion in agar }\end{array}$} \\
\hline & & $0^{c}$ & $24^{c}$ & $48^{r}$ \\
\hline \multicolumn{5}{|l|}{ Toxigenic } \\
\hline K325 & + & - & - & - \\
\hline K344 & + & - & - & - \\
\hline M324 & + & - & - & - \\
\hline M117 & + & - & - & - \\
\hline $\mathrm{K} 100$ & + & - & - & - \\
\hline Control (10405) & - & - & - & - \\
\hline
\end{tabular}

a The supernatant from a stationary-phase TSB culture was tested for toxin.

${ }^{b}$ An appropriate dilution of the stationary-phase TSB culture was filtered.

' Toxin was assayed by extracting the agar with PBS and testing the extract.

TABLE 3. Detection of LT in TSA medium

\begin{tabular}{|c|c|c|c|c|c|c|}
\hline \multirow{3}{*}{ Organism } & \multicolumn{6}{|c|}{ Detection } \\
\hline & \multirow{2}{*}{$\begin{array}{l}\text { In super- } \\
\text { natant }^{a}\end{array}$} & \multicolumn{5}{|c|}{$\begin{array}{l}\text { After following time (h) of } \\
\text { incubation on } \operatorname{TSA}^{b}(\mathrm{~h})\end{array}$} \\
\hline & & $0^{c}$ & $6^{c}$ & $8^{c}$ & $10^{c}$ & $12^{c}$ \\
\hline \multicolumn{7}{|l|}{ Toxigenic } \\
\hline K325 & + & - & + & + & + & + \\
\hline K344 & + & - & + & + & + & + \\
\hline M324 & + & - & + & + & + & + \\
\hline M117 & + & - & + & + & + & + \\
\hline K100 & + & - & + & + & + & + \\
\hline Control (10405) & - & _- & - & - & - & - \\
\hline
\end{tabular}

"The supernatant from a stationary-phase TSB culture was tested for toxin.

${ }^{b}$ Filters were placed on TSA at $37^{\circ} \mathrm{C}$ after $18 \mathrm{~h}$ of incubation on mTEC medium. There were between 10 and 30 colonies on each filter.

'Toxin was assayed by extracting the agar with PBS and testing the extract. component of the mTEC medium still present in the filter. Since toxin was consistently detected in TSA at $6 \mathrm{~h}$, this procedure was followed in all subsequent experiments.

The sensitivity of the Y-1 cells and the effect of the duration of time that the filter was in contact with the cell monolayer were examined (Table 4). A positive response was defined as more than $75 \%$ of the cells within a $3-$ to $5-\mathrm{mm}$ circle drawn on the plate immediately below the $E$. coli colony exhibiting characteristic rounding (cytotonic effect). All Y-1 monolayers were exmained 15 to $24 \mathrm{~h}$ after exposure to the filter. It was clear that the monolayer only required a 15 min exposure to the filter. A longer exposure gave no increase in the response and had no adverse effect on the Y-1 cells. The Y-1 cells exposed to areas of the filter which were devoid of ETEC colonies showed no morphological changes. After a 15-min exposure of the monolayer to a filter on which there were 34 or more colonies, the cytotonicity was confluent, probably the result of diffusion of the toxin. However, a single toxigenic colony on a filter was detectable.

It is important to have a confluent Y-1 monolayer for the assay of ETEC colonies. A plate with a low density of Y-1 cells may not have cells under the $E$. coli colonies and, therefore, give no indication of ETEC present in the sample. Another problem was the removal of Y-1 cells from the plate due to their adherence to the filter when it was removed. This problem was obviated by leaving a small amount of buffer to provide an interface between the cells and the filter. The small-volume buffer which remained had no effect on the ability to detect toxin.

Differentiation of toxigenic strains from nontoxigenic strains by the combination of mTEC and Y-1 monolayer (MY-1) procedures in a mixed population was studied by assaying mixtures of strain K325 and the nontoxigenic strain 10405 (Table 5). As few as 2 toxigenic colonies in 40 nontoxigenic colonies were detected, and 30 or more toxigenic colonies on a plate gave confluent cytotonicity.

Water samples from three sites on upper Narragansett Bay and two sites in Boston Harbor yielded high densities of $E$. coli $\left(10^{4}\right.$ and $10^{3} / 100$ $\mathrm{ml}$, respectively), but in more than 300 colonies examined (Table 6), no toxigenic strains were detected. To determine whether background microorganisms had any effect on toxigenic strains, a water sample was seeded with a culture of strain K325. The fact that $100 \%$ of the K325 organisms were detected indicates that there were few (if any) ETEC present in the original water samples. No false-positive colonies were noted.

Five fecal samples (courtesy of S. T. Donta, 
TABLE 4. Effect of time on detection of LT-producing colonies on Y-1 monolayers

\begin{tabular}{|c|c|c|c|c|c|c|}
\hline \multirow{3}{*}{ Organism } & \multicolumn{6}{|c|}{ No. of colonies at following exposure time $(\mathrm{min})$ of Y-1 monolayer to filter ${ }^{\prime \prime}$} \\
\hline & \multicolumn{2}{|c|}{15} & \multicolumn{2}{|c|}{30} & \multicolumn{2}{|c|}{45} \\
\hline & Expected $^{b}$ & Observed $^{c}$ & Expected $^{h}$ & Observed ${ }^{c}$ & Expected $^{h}$ & Observed ${ }^{*}$ \\
\hline \multicolumn{7}{|l|}{ Toxigenic } \\
\hline K325 & 6 & 6 & 15 & 15 & 14 & 14 \\
\hline K344 & 54 & $+^{d}$ & 8 & 8 & 6 & 6 \\
\hline M324 & 51 & + & 9 & 9 & 6 & 6 \\
\hline M117 & 34 & + & 58 & + & 4 & 4 \\
\hline K100 & 25 & 25 & 1 & 1 & 14 & 14 \\
\hline Control (10405) & 62 & 0 & 62 & 0 & $\mathrm{ND}^{e}$ & ND \\
\hline
\end{tabular}

a All filters had been incubated on mTEC medium $(18 \mathrm{~h})$ and transferred to TSA $(6 \mathrm{~h})$ before being placed on the Y-1 monolayer.

${ }^{b}$ Number of colonies expected on filter based on a calculation from dilutions.

' Number of cytotonic zones on Y-1 monolayer.

${ }^{d}+$, Confluent cytotonicity.

'ND, No data.

TABLE 5. Assay of toxigenic and nontoxigenic colonies in a mixed population

\begin{tabular}{|c|c|c|c|c|c|}
\hline \multirow{2}{*}{ Trial } & \multirow{2}{*}{$\begin{array}{l}\text { Total } \\
\text { colo- } \\
\text { nies }\end{array}$} & \multicolumn{2}{|c|}{ Toxigenic colonies } & \multicolumn{2}{|c|}{$\begin{array}{l}\text { Nontoxigenic col- } \\
\text { onies }\end{array}$} \\
\hline & & $\begin{array}{c}\text { Ex- } \\
\text { pected }^{h}\end{array}$ & $\begin{array}{c}\text { Ob- } \\
\text { served }^{c}\end{array}$ & $\begin{array}{c}\text { Ex- } \\
\text { pected }\end{array}$ & $\begin{array}{c}\text { Ob- } \\
\text { served }\end{array}$ \\
\hline 1 & 29 & 30 & $+^{e}$ & 0 & 0 \\
\hline 2 & 68 & 0 & 0 & 68 & 68 \\
\hline 3 & 65 & 3 & 3 & 61 & 62 \\
\hline 4 & 49 & 27 & + & 7 & 0 \\
\hline 5 & 40 & 3 & 2 & 28 & 38 \\
\hline 6 & 31 & 12 & 10 & 7 & 21 \\
\hline 7 & 63 & $<1$ & 0 & 68 & 63 \\
\hline 8 & 31 & 30 & + & $<1$ & 0 \\
\hline
\end{tabular}

${ }^{a}$ Number of colonies on a filter.

${ }^{b}$ Expected number of colonies based on calculations from dilutions.

' Number of cytotonic zones.

${ }^{d}$ Number of colonies not associated with cytotonic zones.

${ }^{e}+$, Confluent cytotonicity.

University of Iowa, Iowa City) known to contain ETEC were examined by the MY-1 procedure. Three dilutions of each sample were processed. Toxigenic zones were detected in all cases (Table 7). An accurate estimation of the number of colonies on the filters from samples 76 and 105 was not possible, and estimates of 100 and 200 colonies per filter, respectively, were used. The presence of three to four cytotonic zones under the filter from sample 76 indicates that there were, in fact, only three or four ETEC organisms per filter. However, the presence of 27 to 29 zones under the filter from sample 105 must be interpreted as a minimum number of ETEC present, since more than one organism could have been responsible for 1 zone of cytotonicity.
TABLE 6. Examination of toxigenic and nontoxigenic colonies of $E$. coli in water sample from estuaries

\begin{tabular}{lcc}
\hline Location of site & $\begin{array}{c}\text { No. of } E \text {. coli } \\
\text { colonies ob- }^{a} \text { served }^{b}\end{array}$ & $\begin{array}{c}\text { No. of LT } \\
\text { colonies de- }^{\text {tected }}\end{array}$ \\
\hline Narragansett Bay & $73^{d}$ & 0 \\
1 & 138 & 0 \\
2 & 106 & 0 \\
3 & 82 & $66^{f}$ \\
$4^{e}$ & & \\
Boston Harbor & 112 & 0 \\
1 & 99 & 0 \\
2 & & \\
\hline
\end{tabular}

"Both locations were known to be heavily contaminated with raw sewage.

${ }^{b}$ Amount is based on the mTEC procedure.

' MY-1 procedure (filter placed on Y-1 monolayer after $6 \mathrm{~h}$ on TSA).

${ }^{d}$ Total number of colonies on two or three replicate filters.

' Sample from site 3 seeded with strain K325 (toxigenic).

${ }^{f}$ One hundred percent recovery of strain K325.

\section{DISCUSSION}

The role of LT-producing ETEC in diarrhea, particularly severe cholera-like diarrhea (13), has become increasingly significant (11) especially in underdeveloped countries where ETEC is endemic in some areas (5). Large numbers of environmental and fecal samples must be examined for LT-producing $E$. coli to determine the prevalence and source of ETEC. The MY-1 procedure is an inexpensive, rapid, and accurate assay method of field and clinical samples for LT-producing strains and permits the assay of the large number of samples required for epidemiological investigations. Cultural examination 
TABLE 7. Quantification of ETEC in fecal specimens by the MY.1 procedure ${ }^{\prime \prime}$

\begin{tabular}{ccc}
\hline Sample $^{b}$ & $\begin{array}{c}\text { No. of } E \text {. coli colo- } \\
\text { nies observed }\end{array}$ & $\begin{array}{c}\text { No. of ETEC col- } \\
\text { onies detected }\end{array}$ \\
\hline 74 & $43^{\prime \prime}$ & $3^{e}$ \\
75 & 43 & 24 \\
76 & 200 & 7 \\
104 & 82 & 5 \\
105 & 400 & 57 \\
\hline
\end{tabular}

\footnotetext{
"MY-1 procedure (filter placed on Y-1 monolayer after $6 \mathrm{~h}$ on TSA).

${ }^{b}$ Known positive ETEC fecal samples.

" mTEC medium used for initial assay.

"Total number of colonies on duplicate plates.

' Zones of cytotonicity counted.
}

of the isolates may then be conducted to confirm toxin-producing ability.

Although ETEC were not found in Narragansett Bay or Boston Harbor, this was not totally unexpected since ETEC are generally associated with the chronic unsanitary conditions of underdeveloped nations and are not believed to be present in the United States (11), although ETEC diarrhea is found among young farm animals (2), suggesting that ETEC may be present in the environment in small numbers. This low incidence of ETEC in our environment, if verified, may explain the high incidence of ETEC traveler's diarrhea in U.S. citizens visiting those countries $(1,7,9)$.

The recovery of ETEC from fecal samples showed that the MY-1 procedure could detect ETEC from a clinical specimen. With this procedure, it will now be possible to determine the ratio of ETEC to nontoxigenic $E$. coli in a fecal population.

The mTEC technique has recently been improved (A. Dufour and E. Strickland, Abstr. Annu. Meet. Am. Soc. Microbiol. 1979, Q61, p. 229) to increase the overall recovery, and this improvement may also increase the recovery of toxigenic strains. Toxigenic $E$. coli were not detected on Y-1 cells, unless filters containing colonies were transferred from mTEC medium to TSA and incubated; hence, mTEC agar appeared to inhibit the production of toxin. However, this inhibition was not permanent, and the toxin was expressed after an additional incubation on TSA. Inhibition of toxin production by mTEC was not investigated. This inhibition is believed to be due to either the high temperature of incubation $\left(44^{\circ} \mathrm{C}\right)$ or the acid produced by $E$. coli in utilizing the lactose in the medium or both. The MY-1 procedure detects LT-producing strains in both pure and mixed cultures. This method is therefore well adapted to field studies where mixed populations are present.
With the MY-1 procedure, the time required for detecting toxigenic colonies is less than that for the conventional system. In less than $48 \mathrm{~h}$, tests of 250 colonies for LT production can be completed. The time required for the preparation and examination of the test was approximately $4 \mathrm{~h}$, much less than the time required even by the microtiter technique (9).

Since some LT-producing strains lose the ability to produce toxin upon laboratory passage (11), a reduction in processing and assay time may increase the number of ETEC detected. This rapid, simple, and quantitative method for detecting and enumerating LT-producing $E$. coli can also be applied toward studies of clinical investigation, colonization, and genetics, particularly those that characterize plasmid(s)-mediating toxin production.

\section{LITERATURE CITED}

1. Donta, S. T. 1976. Gastroenterologists on the move: the nature of Traveler's diarrhea. N. Engl. J. Med. 194: 1340-1341.

2. Donta, S. T., H. W. Moon, and S. C. Whipp. 1974 Detection of heat-labile Escherichia coli enterotoxin with the use of adrenal cells in tissue culture. Science 189:334-336.

3. Donta, S. T., H. W. Moon, S. C. Whipp, and S. M. Skartvedt. 1974. In vitro production and inactivation of Escherichia coli enterotoxin. Gastroenterology 67: 983-990.

4. Dufour, A. P., E. R. Strickland, and V. J. Cabelli. 1975. A membrane filter procedure for enumerating thermotolerant Escherichia coli, p. 79-81. In D. S. Wilt (ed.), Proceedings, 9th National Shellfish Sanitation Workshop. U.S. Food and Drug Administration, Charleston, S.C

5. Echeverria, P. 1978. Search for heat-labile enterotoxigenic Escherichia coli in humans, livestock, food, and water in a community in the Philippines. J. Infect. Dis. 138:87-90.

6. Geldreich, E. E., H. L. Jeter, and J. A. Winter. 1967. Technical considerations in applying the membrane filter procedure. Health Lab. Sci. 4:113-125.

7. Gorbach, S. L., B. H. Kean, D. G. Evans, D. J. Evans, and D. Bessudo. 1975. Traveler's diarrhea and toxigenic Escherichia coli. N. Engl. J. Med. 292:933-936.

8. Gordon, J. E. 1971. Diarrheal disease of early childhood-worldwide scope of the problem. Ann. N.Y. Acad. Sci. 176:9-15.

9. Merson, N. H., G. K. Morris, D. A. Sack, et al. 1976. Traveler's diarrhea in Mexico: a prospective study of physicians and family members attending a congress. N. Engl. J. Med. 294:1299-1305.

10. Morgan, G. B., P. Gubbins, and V. Morgan. 1966. A critical appraisal of the membrane filter technique. Health Lab. Sci. 2:227-237.

11. Morris, G. K., M. H. Merson, D. A. Sack, J. G. Wells, W. T. Martin, W. E. Dewitt, J. C. Feeley, R. B. Sack, and D. M. Bessudo. 1976. Laboratory investigation of diarrhea in travelers to Mexico: evaluation of methods for detecting enterotoxigenic Escherichia coli. J. Clin. Microbiol. 3:486-495.

12. Sack, R. B. 1975 . Human diarrheal disease caused by enterotoxigenic Escherichia coli. Annu. Rev. Microbiol. 29:333-353

13. Sack, R. B., W. L. Gorbach, J. G. Banwell, et al. 1971 Enterotoxigenic Escherichia coli isolated from patients with severe cholera-like disease. J. Infect. Dis. 123:378385. 